\title{
Length of time periods in treatment effect descriptions and willingness to initiate preventive therapy: a randomised survey experiment
}

\author{
Erik Berglund ${ }^{1 *}$ (D), Ragnar Westerling ${ }^{1}$, Johan Sundström² and Per Lytsy ${ }^{1}$
}

\begin{abstract}
Background: Common measures used to describe preventive treatment effects today are proportional, i.e. they compare the proportions of events in relative or absolute terms, however they are not easily interpreted from the patient's perspective and different magnitudes do not seem to clearly discriminate between levels of effect presented to people.

Methods: In this randomised cross-sectional survey experiment, performed in a Swedish population-based sample ( $n=1041$, response rate 58.6\%), the respondents, aged between 40 and 75 years were given information on a hypothetical preventive cardiovascular treatment. Respondents were randomised into groups in which the treatment was described as having the effect of delaying a heart attack for different periods of time (Delay of Event, DoE): 1 month, 6 months or 18 months. Respondents were thereafter asked about their willingness to initiate such therapy, as well as questions about how they valued the proposed therapy.

Results: Longer DoE:s were associated with comparatively greater willingness to initiate treatment. The proportions accepting treatment were 81,71 and $46 \%$ when postponement was 18 months, 6 months and 1 month respectively. In adjusted binary logistic regression models the odds ratio for being willing to take therapy was 4.45 (95\% Cl 2.72-7.30) for a DoE of 6 months, and 6.08 (95\% Cl 3.61-10.23) for a DoE of 18 months compared with a DoE of 1 month. Greater belief in the necessity of medical treatment increased the odds of being willing to initiate therapy.

Conclusions: Lay people's willingness to initiate preventive therapy was sensitive to the magnitude of the effect presented as DoE. The results indicate that DoE is a comprehensible effect measure, of potential value in shared clinical decision-making.
\end{abstract}

Keywords: Medical decision-making, Risk communication, Risk perception, Necessity-concern framework

\section{Background}

Insufficient adherence to cardiovascular treatments is considered an important factor in treatment failure [1], and insufficient adherence may increase cardiovascular morbidity [2, 3]. Several studies link patient/personcentred care (PCC) to adherence, as part of a successful preventive medical treatment strategy $[4,5]$. To enable

\footnotetext{
* Correspondence: Erik.Berglund@pubcare.uu.se

${ }^{1}$ Department of Public Health and Caring Sciences, Uppsala University, Box

564, SE-751 22 UPPSALA, Sweden

Full list of author information is available at the end of the article
}

optimal adherence, using a patient-centred approach and informed decision-making, patients need to receive treatment information that is both correct and easy to understand. Statistical effect measures from clinical trials are known to influence patients' views and understandings of a treatment, and it has been shown that the format of the effect measure communicated influences decisions by both physicians and patients [6-9]. The most common measures used to describe a preventive treatment effect include relative risk reductions (RRR) and absolute measures such as absolute risk reductions

(c) The Author(s). 2018 Open Access This article is distributed under the terms of the Creative Commons Attribution 4.0 International License (http://creativecommons.org/licenses/by/4.0/), which permits unrestricted use, distribution, and reproduction in any medium, provided you give appropriate credit to the original author(s) and the source, provide a link to the Creative Commons license, and indicate if changes were made. The Creative Commons Public Domain Dedication waiver (http://creativecommons.org/publicdomain/zero/1.0/) applies to the data made available in this article, unless otherwise stated. 
(ARR) and numbers-needed-to-treat (NNT) [10]. These measures are proportional, i.e. they compare the proportions of events in relative or absolute terms. RRRs have, compared to ARRs and NNTs been shown to score more favourably in evaluations of treatments [10,11]. RRRs, however, does not account for of the baseline risk and are, thus, alone not sufficient to distinguish a treatment effect that is clinically valuable from one that is not. Furthermore, different magnitudes of RRRs do not seem to clearly discriminate between levels of effect presented to lay people [12]. It has been argued that the amplification effect, following a RRR effect description, biases or misleads patients towards accepting interventions in a way that is not consistent with their own values $[13,14]$. For that reason, RRRs are not alone recommended in shared decision making. In a search for effect measures that are appropriate for communication of risk and treatment effect in the preventive setting, different measures depicting postponement of events, time-to-event or prolongation of life have been suggested [15-18]. A gain in disease free time or a gain in life expectancy estimates treatment effect in a way that might be of intuitive value to patients. Lay people seems to have the capacity to determine and choose between different levels of treatment effect in settings such as hip fracture [17] and heart attack [18], when the treatment effect is explained as postponements of time to events. Such time estimations studies have, hitherto, used hypothesised or extrapolated data, which proves the concept of time-based measures, but provides little value for risk and effect communication in clinical practice. A set of complementary measures that go beyond the proportional measures has recently been proposed, that involve assessing between-group differences in percentiles of the survival function [19-21]. By the use of Laplace regression modelling [22], it is possible to assess a treatment effect as the time an event is delayed due to treatment, which can be expressed as the Delay of Event (DoE) measure [19]. The DoE measure evaluates the time difference between two treatment arms at equal event rates. Over the follow-up period, it presents a curve of how the treatment effect develops over time, which has been exemplified using data from clinical studies $[19,21]$. The DoE is an absolute measure and conditional on the event. This means that for a study participant who would have an event during the follow-up without treatment, the DoE depicts the time of the delay when treated. A person who does not experience the event of interest during a follow-up cannot benefit from treatment during this period. The DoE is a complimentary effect measure, and recent results suggest that the DoE compares well to RRR and better than ARR when measuring laymen's willingness to initiate a hypothetical preventive treatment [20].

The objective of this study was to investigate if the length of time in the DoE measure influences lay people's willingness to initiate a preventive treatment against cardiovascular disease (CVD). Secondary objectives were to investigate how the different magnitudes of DoE treatment effects affect individuals' understanding and confidence in the medication and their willingness to pay for treatment (WTP). We hypothesised that people's preference for a preventive therapy is positively influenced by the length of the delayed disease when it is expressed in terms of DoE.

\section{Methods \\ Design and sample}

This is a cross-sectional randomised survey experiment $[23,24]$, in a population-based sample, aged $45-75$ years. Eighteen hundred (1800) randomly selected persons from the Swedish national population registry were randomly allocated into three equally sized groups. The groups received information about a hypothetical treatment's effect as three different delayed event times of heart attack: 1 month, 6 months or 18 months and were then asked different follow-up questions. The questionnaire was returned by 1041 individuals; 23 persons could not be reached or declined to participate, and 736 did not answer, making the response rate of the distributed questionnaires $58.6 \%(1041 / 1777)$. The response rate in the three groups varied from 56.8 to $59.8 \%$. Data were collected from November 2013 to February 2014. A previous study compared the 18 months DoE arm to proportional effect measures [20].

\section{Background questions}

Background data were assessed using questions about the respondent's gender (dichotomous variable), age (continuous variable), and educational level (categorised in three groups).

\section{History of cardiovascular disease}

Data were collected using questions about history of CVD (dichotomised to having had myocardial infarction and/or angina, or not); these questions have been used in previous studies $[25,26]$.

\section{Beliefs about medicines}

Patients beliefs was assessed using the Necessity-Concern Framework (NCF) which was developed specifically to address views of drug treatments [27]. According to the $\mathrm{NCF}$, a patient's decision regarding approving and adhering to a treatment is the result of a trade-off between the patient's perceived need for a prescribed treatment (necessity) and their worries about potential adverse effects as a result of the treatment (concern). NCF has been used in a broad range of different quantitative studies exploring drug treatment adherence [28-31], including cardiovascular diseases [32-35]. NCF was assessed by using the 
Beliefs about Medicines Questionnaire (BMQ) in specific version [27]. The BMQ questionnaire has been translated into Swedish and has been used previously in Sweden [26, 36-39].

\section{Hypothetic scenario and treatment effect information}

The study was conducted as an information intervention with randomised groups in a survey experiment. Respondents were asked to imagine a scenario where they had an increased risk of CVD, and that their physician suggested a preventive cardiovascular drug treatment (comparable to statin treatments). The text was outlined: "Imagine that in the next five years you will have an increased risk of having a heart attack. Your physician offers you a treatment with rare and mild side effects, to be taken in pill form once a day. The usefulness of the treatment has been evaluated in scientific studies, and the effect can be described as follows: If you would have a heart attack in the next 5 years it will be delayed for up to [ 1 month] if you take the treatment." The text describing the effect measure, in square brackets above, expressed different magnitudes of the Delay of Event measure. The first group received a treatment effect described as 1 month DoE, the second group 6 months DoE, and the third group 18 months DoE.

\section{Outcome variables}

Information about willingness to initiate treatment, the dependent variable in the analyses, was assessed using the question: "If you were in the same situation as the person in this case would you take the treatment?". Response alternatives were yes or no. Other questions that were used to evaluate the views of the treatment were: "How much benefit do you assess that the drug would have?"; "Would you feel safe to take the drug?"; "Would you, based on the description, be motivated to take the medication on a daily basis?"; "How important is it to adhere to the treatment prescription?" and "To what extent does the description help you make a medical decision?". The answers to these questions were assessed on seven-point Likert scales ranging from: 1 (not at all) to 7 (very much). Little is known about the monetary value that individuals assign in relation to the proposed medication. Willingness to pay (WTP) is an assessment of the highest price an individual will pay for a good or service [40]. WTP was assessed with an open-ended question: "What is the maximum amount of money that you would pay per month during a five-year period to receive the treatment?". WTP was measured in Swedish currency (SEK), and for the purpose of this study was converted to Euros $(€)$ at an exchange rate of 0.10.

\section{Statistical analysis}

Chi-square analyses and multivariate logistic regression analyses were used to investigate associations between willingness to initiate therapy and the presented DoE magnitudes. Associations between lay people's views of the treatment descriptions, WTP and presented DoE magnitudes were tested with Kruskal-Wallis $\mathrm{H}$ tests. Consent to initiate preventive therapy was tested in multivariate binary logistic regression models. A stepwise approach was performed to build these models. Model 1 included length of time delay and demographics. Model 2 included model 1, history of cardiovascular diseases and NCF. In order to examine the interaction effects of DoE and age group (categorised as over/under 60 years of age), multiplicative interaction terms of length of time delay $\times$ age group were included in model 3. Statistical Package for the Social Sciences (SPSS) ${ }^{\circ}$ version 22 (IBM SPSS Statistics for Windows, Armonk, NY: IBM Corp Chicago, IL, U.S.A.) was used for descriptive statistics and statistical tests. A $p$-value $\leq 0.05$ was considered statistically significant.

\section{Results}

The study population was on average 61.8 years old and consisted of slightly more women than men. College or university was the most common completed education level. A distribution of demographic variables, overall and according to group allocation, is shown in Table 1. In the study population the prevalence of a history of cardiovascular disease (heart attack and/or angina) was $5.8 \%$. Overall the three groups were well balanced in baseline characteristics.

\section{Decision to initiate treatment and views of treatment}

Overall, $65.4 \%$ of the respondents were willing to take the suggested medication. The proportions accepting the treatment were 80.5, 70.6 and $45.5 \%$, for a DoE of 18 months, 6 months and 1 month, respectively. The difference was statistically significant between the three groups (Table 2).

There were statistically significant differences between the three groups due to the presented DoE regarding respondents' views of the benefit from treatment, feeling safe to take the drug, motivation to take treatment, views on importance of adhering to prescription, and WTP. The longer time periods presented as DoE, the more favourable did the respondents consider the drug. The median WTP for the three different treatment descriptions ranged from $€ 13.4$ for DoE of 1 month, $€ 23.2$ for DoE of 6 months, to $€ 25.7$ for DoE of 18 months ( $P$ $<0.001)$. There was no difference in use of information from prescriptions (Table 2).

\section{Logistic regressions}

The willingness to initiate therapy was further explored in logistic regression models (Table 3). The odds of being willing to initiate treatment increased with a longer 
Table 1 Distribution of characteristics among participants

\begin{tabular}{|c|c|c|c|c|c|}
\hline \multirow[b]{2}{*}{ Category } & \multirow[b]{2}{*}{ Subcategory } & \multicolumn{4}{|c|}{ Delay of Events } \\
\hline & & 1 month & 6 months & 18 months & Overall \\
\hline \multirow[t]{2}{*}{ Gender } & Men, \% (n) & $48.6(169)$ & $40.2(141)$ & $44.3(148)$ & $44.3(458)$ \\
\hline & Women, \% (n) & $51.4(179)$ & $59.8(210)$ & $55.7(186)$ & $55.7(575)$ \\
\hline Age & Mean (SD) & $61.7(8.5)$ & $61.8(8.7)$ & $61.8(8.6)$ & $61.8(8.6)$ \\
\hline \multirow[t]{3}{*}{ Education level } & Compulsory school, \% (n) & $27.2(94)$ & $29.0(101)$ & $27.5(92)$ & $27.9(287)$ \\
\hline & Secondary school, \% (n) & $35.9(124)$ & $35.3(123)$ & $35.8(120)$ & $35.7(367)$ \\
\hline & College or university, \% (n) & $36.8(127)$ & $35.6(124)$ & $36.7(123)$ & $36.4(374)$ \\
\hline \multirow[t]{2}{*}{ History of cardiovascular disease } & Have had heart attack or angina, \% (n) & $7.4(25)$ & $5.5(19)$ & $4.5(15)$ & $5.8(59)$ \\
\hline & No history of heart attack or angina, \% (n) & $92.6(315)$ & $94.5(327)$ & $95.5(315)$ & $94.2(957)$ \\
\hline \multirow[t]{2}{*}{ Necessity-concern Framework } & Necessity, median ${ }^{\mathrm{a}}$ (mean) & $12(12.1)$ & $11(11.0)$ & $12(12.6)$ & $12(11.6)$ \\
\hline & Concern, median (mean) & $4(4.8)$ & $3(4.4)$ & $4(5.1)$ & $4(4.8)$ \\
\hline
\end{tabular}

Figures as percentages and numbers $(\mathrm{n}$ ) if not stated otherwise. Mean values are presented with standard deviation (SD)

${ }^{a}$ Necessity and concern was used in index form, ranging from 0 to 20

DoE, in adjusted models: odds ratio (OR) 4.45 (95\% confidence interval (CI) 2.72-7.30) for a DoE of 6 months, OR 6.08 (95\% CI 3.61-10.23) for a DoE of 18 month compared with a DoE of 1 month (reference category). The results were similar also when interaction terms were included in the model: OR 5.51 (95\% CI 2.4712.30) for a DoE of 6 months and OR 5.69 (95\% CI 2.44-13.27) for a DoE of 18 months. A higher perceived necessity of medication in medical treatments in the NCF slightly increased the odds (OR 1.07, CI 1.03-1.11) for being willing to initiate therapy. Having a history of cardiovascular disease (heart attack and/or angina) was significantly associated with having a higher willingness to initiate treatment in the crude and adjusted models. No statistically significant interaction effect was found between length of time delay and age group.

\section{Discussion}

This study had the objective of investigating whether the length of time in the Delay of Event measure affected lay peoples' willingness to accept a proposed treatment.
This study also aimed to investigate how the different time periods of delay affect individuals' evaluation and confidence in a proposed treatment as well as their willingness to pay for a therapy with a certain stated effect.

A higher proportion of individuals were willing to accept the treatment when the effect was presented with a greater time period in DoE. These findings are in agreement with similar studies that have demonstrated that lay people's choices are sensitive to length of time periods of a treatment effect when it is expressed as postponements in time $[17,18]$. Time-based measures, such as DoE, are considered to be easier to comprehend than proportional measures [18]. The results in the present study suggest that time-based measures of treatment effects enable lay people to evaluate and choose between different magnitudes of delay, in contrast to RRR measures which do not help lay people to a sufficient extent [12].

Relative measures of risk reductions depict a perspective that is relevant to individual patients. Relative risk reductions are usually relatively stable over the follow-up time

Table 2 Treatment decision and evaluation of descriptions

\begin{tabular}{|c|c|c|c|c|c|c|}
\hline \multirow[b]{2}{*}{ Outcome } & \multicolumn{6}{|c|}{ Delay of Events } \\
\hline & 1 month & 6 months & 18 months & Overall & CHI-Square & $P$-value \\
\hline Willingness to initiate treatment, \% (n) & $45.5(156)$ & $70.6(243)$ & $80.5(268)$ & $65.4(667)$ & $98.71^{a}$ & $<0.001$ \\
\hline Benefit from medication, $m d(q 1, q 3), m$ & $3(2,5), 3.18$ & $4(2,5), 3.99$ & $5(4,6), 4.58$ & $4(2,5), 3.91$ & $96.20^{\mathrm{b}}$ & $<0.001$ \\
\hline Feel safe with medication, $m d(q 1, q 3), m$ & $3(2,5), 3.45$ & $4(2,5), 3.95$ & $4(3,6), 4.25$ & $4(2,5), 3.88$ & $30.35^{b}$ & $<0.001$ \\
\hline Be motivated to take medication, $\mathrm{md}(\mathrm{q} 1, \mathrm{q} 3), \mathrm{m}$ & $2(1,5), 3.17$ & $4(2,6), 4.09$ & $5(3,6), 4.66$ & $4(2,6), 3.97$ & $79.64^{b}$ & $<0.001$ \\
\hline Importance to adhere, md, (q1, q3), m & $5(2,7), 4.47$ & $6(4,7), 5.27$ & $5(5,7), 5.67$ & $6(4,7), 5.13$ & $41.91^{b}$ & $<0.001$ \\
\hline Willingness to pay (Euro), md (q1, q3), $m^{c}$ & $5(0,16), 13.4$ & $10(5,30), 23.2$ & 20 (10,30), 25.7 & $10(0,30), 20.8$ & $65.10^{b}$ & $<0.001$ \\
\hline Use of information, md (q1, q3), m & $5(3,6), 4.63$ & $5(4,6), 4.65$ & $5(4,6), 4.91$ & $5(4,6), 4.72$ & $3.25^{\mathrm{b}}$ & 0.20 \\
\hline
\end{tabular}

apearson Chi-Square

${ }^{\mathrm{b}}$ Kruskal-Wallis $\mathrm{H}$ test

'Willingness to pay was measured in Swedish krona (SEK) 1SEK/0.10 Euro (€) 
Table 3 Multivariate models of the odds of consenting to therapy

\begin{tabular}{|c|c|c|c|c|c|}
\hline & & $\begin{array}{l}\text { Crude } \\
\text { OR 95\% Cl }\end{array}$ & $\begin{array}{l}\text { Model } 1 \\
\text { OR 95\% Cl }\end{array}$ & $\begin{array}{l}\text { Model } 2 \\
\text { OR 95\% Cl }\end{array}$ & $\begin{array}{l}\text { Model } 3 \\
\text { OR 95\% Cl }\end{array}$ \\
\hline \multirow[t]{4}{*}{ Delay of Events (DoE) } & Length of time delay & & & & \\
\hline & 1 month (ref. cat.) & 1 & 1 & 1 & 1 \\
\hline & 6 month & $\begin{array}{l}2.88^{* *}(2.11 \text { to } \\
3.95)\end{array}$ & $\begin{array}{l}3.01^{* *}(2.17 \text { to } \\
4.16)\end{array}$ & $\begin{array}{l}4.45^{* *}(2.72 \text { to } \\
7.30)\end{array}$ & $\begin{array}{l}5.51^{* *}(2.47 \text { to } \\
12.30)\end{array}$ \\
\hline & 18 month & $\begin{array}{l}4.94^{* *} \text { (3.50 to } \\
6.97)\end{array}$ & $\begin{array}{l}5.15^{* *} \text { (3.62 to } \\
7.33)\end{array}$ & $\begin{array}{l}6.08^{* *}(3.61 \text { to } \\
10.23)\end{array}$ & $\begin{array}{l}5.69^{* *}(2.44 \text { to } \\
13.27)\end{array}$ \\
\hline \multirow[t]{10}{*}{ Demographic } & Gender & & & & \\
\hline & Male (ref. cat.) & 1 & 1 & 1 & 1 \\
\hline & Female & 1.11 (0.85 to 1.43$)$ & $1.02(0.77$ to 1.35$)$ & 0.87 (0.56 to 1.33 ) & 0.87 (0.57 to 1.32 ) \\
\hline & Age group & & & & \\
\hline & under 60 years of age (ref. cat.) & 1 & 1 & 1 & 1 \\
\hline & 60 years of age or older & $\begin{array}{l}1.80^{* *}(1.35 \text { to } \\
1.28)\end{array}$ & $\begin{array}{l}1.64^{* *}(1.12 \text { to } \\
2.20)\end{array}$ & 1.34 (0.87 to 2.07$)$ & 1.45 (0.76 to 2.70$)$ \\
\hline & Education level & & & & \\
\hline & University (ref. cat.) & 1 & 1 & 1 & 1 \\
\hline & Secondary school or equal & $\begin{array}{l}1.43^{*}(1.06 \text { to } \\
1.93)\end{array}$ & $\begin{array}{l}1.54^{* *}(1.12 \text { to } \\
2.12)\end{array}$ & 1.13 (0.70 to 1.83$)$ & 1.12 (0.69 to 1.81$)$ \\
\hline & Compulsory school & $\begin{array}{l}2.28^{* *}(1.62 \text { to } \\
3.20)\end{array}$ & $\begin{array}{l}2.19^{* *}(1.51 \text { to } \\
3.17)\end{array}$ & $1.87^{*}(1.11$ to 3.16$)$ & $1.89^{*}(1.12$ to 3.19 \\
\hline \multirow{3}{*}{$\begin{array}{l}\text { History of cardiovascular } \\
\text { diseases }\end{array}$} & History of heart attack or angina & & & & \\
\hline & No (ref. cat.) & 1 & & 1 & 1 \\
\hline & Had heart attack and/or angina & $\begin{array}{l}3.47^{* *}(1.62 \text { to } \\
7.41)\end{array}$ & & $2.89^{*}(1.13$ to 7.41$)$ & $2.86^{*}(1.11$ to 7.36 \\
\hline \multirow{3}{*}{$\begin{array}{l}\text { Necessity concerns } \\
\text { framework }^{\mathrm{a}}\end{array}$} & Beliefs about medicine & & & & \\
\hline & Necessity & $\begin{array}{l}1.06^{* *}(1.03 \text { to } \\
1.10)\end{array}$ & & $\begin{array}{l}1.07^{* *}(1.03 \text { to } \\
1.11)\end{array}$ & $\begin{array}{l}1.07^{* *}(1.03 \text { to } \\
1.11)\end{array}$ \\
\hline & Concern & 1.03 (0.99 to 1.07$)$ & & $1.00(0.95$ to 1.05$)$ & 1.00 (0.95 to 1.05$)$ \\
\hline \multirow[t]{2}{*}{ Interaction effect ${ }^{b}$} & $\begin{array}{l}\text { DoE } 6 \text { month } \times 60 \text { years of age or } \\
\text { older }\end{array}$ & 0.98 (0.52 to 1.87$)$ & & & 0.71 (0.26 to 1.92$)$ \\
\hline & $\begin{array}{l}\text { DoE } 18 \text { month } \times 60 \text { years of age or } \\
\text { older }\end{array}$ & 1.18 (0.58 to 2.39$)$ & & & 1.11 (0.38 to 3.22$)$ \\
\hline
\end{tabular}

Odds ratio $(\mathrm{OR})$, significance level and confidence interval $(\mathrm{Cl})$ for willing to initiate therapy $(0=$ "no", $1=$ "yes")

${ }^{a}$ Necessity and concern was used in index form, ranging from 0 to 20

${ }^{b}$ Interaction effects was adjusted for variables included in the interaction term

* $P \leq 0.05$, ** $P \leq 0.01$ Model $1=$ Length of time delay+demographics, Model $2=$ Model $1+$ History of cardiovascular diseases+Necessity concerns framework,

Model $3=$ Model $2+$ interaction effect

and across different risk groups, but they are not easily interpreted from the patient's perspective. This may be because RRRs do not consider the time perspective, which is of profound meaning for patients. RRRs do not apply to the patients' long-term perspective for events that eventually will occur, such as death or other major adverse events of which absolute risk increases with time. This is linked to the fact that RRRs does not account for the underlying absolute risk at baseline. On the other hand, absolute numbers, such as risk differences, are easy to grasp and emphasise the fraction of treated patients that do experience a benefit. Such an interpretation - that only some benefit - is, however, likely to be an underestimation of the effect, as ARRs and NNTs only consider treatment benefit that will persist over the time point of evaluation [41]. Absolute effect measures are further sensitive to the time period of evaluation as well as to the baseline risk of the study population, and is thus of unclear relevance for patients who are likely to be taking the medication on a different timescale than the study population. Time-based non-parametric measures such as the DoE can be favourably expressed as curves, which depict the development of the effect over time and may support wellinformed treatment decisions.

The DoE measure is not an average that applies to everyone which is a potentially difficult aspect in a clinical situation. Rather it is an estimation of the time an event is delayed due to treatment for people who would 
have developed the event, if untreated. To assume that one will have the event might be a cognitive challenge, and there is a risk such an assumption will tend to inflate patients' perceived necessity and concerns of the treatment. If so, it might bias treatment decisions in favour of taking the treatment. On the other hand, if a DoE effect is perceived as short, it might do the opposite. Clinical use of the DoE measure will provide patients and physicians an opportunity to reflect on several important aspects, such as the patient's medical status, risk and the benefits from treatment, which is one of the suggested routines to achieve shared decision making within patient-centred care $[42,43]$. It cannot be taken for granted that different populations will assess the DoE measure in equal ways. The absolute risk of having an event, as well as the perceived severity and consequences of having that event, might vary for different conditions over different populations. For instance, the risk of having an event following a chronic disease usually increases with age. At the same time older age might go with declining quality of life, which may affect the perceived importance of delaying (or avoiding) events. Hence, there is a need to investigate the appropriateness of present treatment effect as DoE, for different conditions and populations.

Our observations suggest that the length of the DoE affects several aspects of lay people's view of the proposed treatment, including their degree of motivation for taking it. The magnitude of the DoE showed no influence on the perceived usefulness of the information provided; consequently the quality of information and the ability to be informed was not dependent on the presented effect. This indicates that the data and their presentation were useful for decision and evaluation of effect, regardless of the presented DoE magnitude. Respondents' willingness to pay for the treatment was higher for longer time periods of DoE. However, the relationship seems to level off in a way sometimes referred to as "the law of diminishing marginal utility", which means that the first unit of consumption of a goods or service yields more utility than the second and subsequent units. In this case lay people tended to have higher WTP for a month in a shorter total time period than for a month in a longer time period. Previous research has discussed diminishing marginal utility in relation to gain of future life-years compared to those at present age. People tend to value life-years in the future less than those at present not because of the timing of these life-years, but simply because a life-year in the distant future implies a long life, which may stand for a satiation effect [44].

No statistically significant interaction effect was found between length of time delay and age group, which suggests that there are no multiplicative effects. However, it is possible that such an interaction exists in other populations, where the events and treatment effects are more closely related to the age.

High belief in treatment necessity in the NCF are known to be associated with adherence and behaviour related to treatment [26]. In this study, greater belief of necessity was associated with increased willingness to initiate therapy; however, adjusting for necessity and concerns did not abolish the effect of an increased DoE effect. The NCF was developed to explore patients' views on drugs in general and not specifically preventive drugs; consequently the measure is not optimal for use in a study with lay people and a hypothetical scenario. The reason for including the NCF in this study was to capture a general attitude to drugs rather than specific benefits/concerns about the treatment presented in the scenario.

To summarise: the results in this study imply that time magnitudes described as DoE are useful for lay people in decision-making regarding medical treatments. The DoE measure might be an adequate alternative, and/or a complement to other treatment descriptions and a useful tool in shared clinical decision-making. This was the first study of differences in magnitudes for DoE and therefore relatively large differences in the time periods were chosen to explore the concept. Future studies should investigate if patients also are sensitive to minor differences in DoE, and if patient groups with different baseline risks and conditions also are sensitive to minor differences in DoE. This study does not compare variations in DoE magnitudes with variations in other measure such as RRRs or ARRs, therefore no conclusion can be drawn on these matters. It is suggested that future studies address the question on how variations of magnitude of different effect measures relates to each other as well as decision-making in different situations. There is a need to further investigate if time-based measures, such as DoE, may have an advantageous role in clinical decision making for specific patient groups and treatments, especially if they may improve long-term adherence.

\section{Strengths and limitations}

The strengths of this study include the community setting and the randomised approach. This study also has some limitations worth noting. The study used a hypothetical scenario and the study population mainly consisted of lay people (without previous heart disease); thus, the study population were different than typical patient groups. The response rate is reasonable according to that anticipated from mailed questionnaire-based studies, but unfortunately there is no information about non-responders. Further, reporting bias may exist due to the nature of self-reported data. 


\section{Conclusion}

Lay people's willingness to initiate preventive therapy was sensitive to the length of time periods when treatment effect was presented as the time-based measure Delay of Event. The results indicate that Delay of Event is a comprehensible measure of effect, which holds potential value for communicating treatment benefit and shared clinical decision-making.

\section{Abbreviations \\ €: Euros; ARR: Absolute risk reductions; BMQ: Beliefs about Medicines Questionnaire; Cl: Confidence interval; CVD: Cardiovascular disease; CVM: Contingent valuation method; DoE: Delay of Event; NCF: Necessity- Concern Framework; NNT: Numbers-needed-to-treat OROdds ratio; PCC: Patient/person-centred care; RRR: Relative risk reductions; SEK: Swedish currency; SPSS: Statistical Package for the Social Sciences; WTP: Willingness to pay \\ Acknowledgments \\ We are grateful to all of the responders who gave up their time to contribute to this research. \\ Funding \\ The study was financially supported by grants from Uppsala University and The Swedish Society of Medicine. The funders had no role in the study design, collection and analysis of the data or in preparation of the manuscript.}

\section{Availability of data and materials}

The datasets used and/or analysed during the current study are available from the corresponding author on reasonable request.

\section{Authors' contributions}

EB designed the study, undertook the statistical modelling and led the writing. $\mathrm{PL}, \mathrm{RW}$ and JS designed the study, contributed to data interpretation, and commented on successive drafts of the manuscript and handling of data. All authors read and approved the final manuscript.

\section{Ethics approval and consent to participate}

Respondents gave informed consent to participation by returning a filled in questionnaire, and the study was approved by the ethical committee at the regional Ethical Committee of Clinical Investigation in Uppsala, with project identification code DNR 2013/269.

\section{Consent for publication}

Not applicable.

\section{Competing interests}

All the authors declare that there is no potential competing interest.

\section{Publisher's Note}

Springer Nature remains neutral with regard to jurisdictional claims in published maps and institutional affiliations.

\section{Author details}

1 Department of Public Health and Caring Sciences, Uppsala University, Box 564, SE-751 22 UPPSALA, Sweden. ${ }^{2}$ Department of Medical Sciences, Uppsala University, Uppsala, Sweden.

Received: 12 October 2017 Accepted: 27 September 2018 Published online: 20 November 2018

\section{References}

1. Cheng CW, Woo KS, Chan JC, Tomlinson B, You JH. Association between adherence to statin therapy and lipid control in Hong Kong Chinese patients at high risk of coronary heart disease. Br J Clin Pharmacol. 2004 58(5):528-35. https://doi.org/10.1111/j.1365-2125.2004.02202.x.
2. Blackburn DF, Dobson RT, Blackburn JL, Wilson TW. Cardiovascular morbidity associated with nonadherence to statin therapy. Pharmacotherapy. 2005; 25(8):1035-43. https://doi.org/10.1592/phco.2005.25.8.1035.

3. Wei L, Wang J, Thompson P, Wong S, Struthers AD, MacDonald TM. Adherence to statin treatment and readmission of patients after myocardial infarction: a six year follow up study. Heart. 2002;88(3):229-33.

4. Robinson JH, Callister LC, Berry JA, Dearing KA. Patient-centered care and adherence: definitions and applications to improve outcomes. J Am Acad Nurse Pract. 2008;20(12):600-7. https://doi.org/10.1111/j.1745-7599.2008. 00360.x.

5. WHO. Adherence to Long-term Therapies: Evidence for action. Geneva: World Health Organization; 2003.

6. Hux JE, Naylor CD. Communicating the benefits of chronic preventive therapy: does the format of efficacy data determine patients' acceptance of treatment? Med Decis Mak. 1995:15(2):152-7.

7. Morris JN, Heady JA, Raffle PA, Roberts CG, Parks JW. Coronary heart-disease and physical activity of work. Lancet. 1953;265(6796):1111-20; concl.

8. Edwards A, Elwyn G, Stott N. Communicating risk reductions. Researchers should present results with both relative and absolute risks. BMJ. 1999: 318(7183):603 author reply -4

9. Nexoe J, Gyrd-Hansen D, Kragstrup J, Kristiansen IS, Nielsen JB. Danish GPs' perception of disease risk and benefit of prevention. Fam Pract. 2002;19(1):3-6.

10. Covey J. A meta-analysis of the effects of presenting treatment benefits in different formats. Med Decis Mak. 2007;27(5):638-54. https://doi.org/10. $1177 / 0272989 \times 07306783$.

11. Misselbrook D, Armstrong D. Patients' responses to risk information about the benefits of treating hypertension. Br J Gen Pract. 2001; 51(465):276-9.

12. Sorensen L, Gyrd-Hansen D, Kristiansen IS, Nexoe J, Nielsen JB. Laypersons' understanding of relative risk reductions: randomised cross-sectional study. BMC Med Inform Decis Mak. 2008:8:31. https://doi.org/10.1186/1472-6947-8-31.

13. Akl EA, Oxman AD, Herrin J, Vist GE, Terrenato I, Sperati F, et al. Using alternative statistical formats for presenting risks and risk reductions. Cochrane Database Syst Rev. 2011;(3):Cd006776. https://doi.org/10.1002/ 14651858.CD006776.pub2.

14. Fagerlin A, Zikmund-Fisher BJ, Ubel PA. Helping patients decide: ten steps to better risk communication. J Natl Cancer Inst. 2011;103(19):1436-43. https://doi.org/10.1093/jnci/djr318.

15. Christensen PM, Brosen K, Brixen K, Kristiansen IS. Expressing effects of osteoporosis interventions in terms of postponing of fractures. Eur J Clin Pharmacol. 2002;58(9):629-33. https://doi.org/10.1007/s00228-002-0526-6.

16. Halvorsen PA, Selmer R, Kristiansen IS. Different ways to describe the benefits of risk-reducing treatments: a randomized trial. Ann Intern Med. 2007;146(12):848-56.

17. Christensen PM, Brosen K, Brixen K, Andersen M, Kristiansen IS. A randomized trial of laypersons' perception of the benefit of osteoporosis therapy: number needed to treat versus postponement of hip fracture. Clin Ther. 2003:25(10):2575-85.

18. Dahl R, Gyrd-Hansen D, Kristiansen IS, Nexoe J, Bo Nielsen J. Can postponement of an adverse outcome be used to present risk reductions to a lay audience? A population survey. BMC Med Inform Decis Mak. 2007:7:8. https://doi.org/10.1186/1472-6947-7-8.

19. Lytsy P, Berglund L, Sundstrom J. A proposal for an additional clinical trial outcome measure assessing preventive effect as delay of events. Eur J Epidemiol. 2012;27(12):903-9. https://doi.org/10.1007/s10654-012-9752-0.

20. Berglund $E$, Westerling $R$, Sundstrom J, Lytsy P. Treatment effect expressed as the novel delay of event measure is associated with high willingness to initiate preventive treatment - a randomized survey experiment comparing effect measures. Patient Educ Couns. 2016. https://doi.org/10.1016/j.pec 2016.07.028.

21. Bellavia A, Wallentin L, Orsini N, James SK, Cannon CP, Himmelmann A, et al. Time-based measures of treatment effect: reassessment of ticagrelor and clopidogrel from the PLATO trial. Open Heart. 2017:4(2):e000557. https://doi. org/10.1136/openhrt-2016-000557.

22. Bottai M, Zhang J. Laplace regression with censored data. Biom J. 2010; 52(4):487-503. https://doi.org/10.1002/bimj.200900310.

23. Sniderman PM, Grob DB. Innovations in experimental Design in Attitude Surveys. Annu Rev Sociol. 1996;22:377-99.

24. Gaines BJ, Kuklinski JH, Quirk PJ. The logic of the survey experiment reexamined. Polit Anal. 2007;15:1):1-20. https://doi.org/10.1093/pan/mpl008. 
25. Lytsy P, Westerling R. Patient expectations on lipid-lowering drugs. Patient Educ Couns. 2007;67(1-2):143-50. https://doi.org/10.1016/j.pec.2007.03.004.

26. Berglund E, Lytsy P, Westerling R. Adherence to and beliefs in lipid-lowering medical treatments: a structural equation modeling approach including the necessity-concern framework. Patient Educ Couns. 2012. https://doi.org/10. 1016/.j.pec.2012.11.001.

27. Horne R, Weinman J, Hankins M. The beliefs about medicines questionnaire: the development and evaluation of a new method for assessing the cognitive representation of medication. Psychol Health. 1999;14:1-24.

28. Aikens JE, Nease DE Jr, Nau DP, Klinkman MS, Schwenk TL. Adherence to maintenance-phase antidepressant medication as a function of patient beliefs about medication. Ann Fam Med. 2005;3(1):23-30. https://doi.org/10. 1370/afm. 238 .

29. Horne R, Weinman J. Self-regulation and self-management in asthma: exploring the role of illness perceptions and treatment beliefs in explaining non-adherence to preventer medication. Psychol Health. 2002;17(1):17-32. https://doi.org/10.1080/08870440290001502.

30. Llewellyn CD, Miners AH, Lee CA, Harrington C, Weinman J. The illness perceptions and treatment beliefs of individuals with severe Haemophilia and their role in adherence to home treatment. Psychol Health. 2003;18(2): 185-200. https://doi.org/10.1080/0887044031000098198.

31. Neame R, Hammond A. Beliefs about medications: a questionnaire survey of people with rheumatoid arthritis. Rheumatology. 2005;44(6):762-7. https:// doi.org/10.1093/rheumatology/keh587.

32. Allen LaPointe NM, Ou FS, Calvert SB, Melloni C, Stafford JA, Harding T, et al. Association between patient beliefs and medication adherence following hospitalization for acute coronary syndrome. Am Heart J. 2011;161(5):85563. https://doi.org/10.1016/j.ahj.2011.02.009.

33. Allen LaPointe NM, Ou FS, Calvert SB, Melloni C, Stafford JA, Harding T, et al. Changes in beliefs about medications during long-term care for ischemic heart disease. Am Heart J. 2010;159(4):561-9. https://doi.org/10.1016/j.ahj. 2009.12.025.

34. Magadza C, Radloff SE, Srinivas SC. The effect of an educational intervention on patients' knowledge about hypertension, beliefs about medicines, and adherence. Res Social Adm Pharm. 2009;5(4):363-75. https://doi.org/10. 1016/j.sapharm.2009.01.004.

35. Sud A, Kline-Rogers EM, Eagle KA, Fang J, Armstrong DF, Rangarajan K, et al. Adherence to medications by patients after acute coronary syndromes. Ann Pharmacother. 2005;39(11):1792-7. https://doi.org/10.1345/aph.1G249.

36. Jorgensen TM, Andersson KA, Mardby AC. Beliefs about medicines among Swedish pharmacy employees. Pharm World Sci. 2006;28(4):233-8. https:// doi.org/10.1007/s11096-005-2907-2.

37. Mardby AC, Akerlind I, Jorgensen T. Beliefs about medicines and selfreported adherence among pharmacy clients. Patient Educ Couns. 2007; 69(1-3):158-64. https://doi.org/10.1016/.jpec.2007.08.011.

38. Mardby AC, Akerlind I, Hedenrud T. Different development of general beliefs about medicines during undergraduate studies in medicine, nursing and pharmacy. Patient Educ Couns. 2009;75(2):283-9. https://doi.org/10. 1016/.jpec.2008.10.012

39. Mardby AC, Akerlind I, Hedenrud T. General beliefs about medicines among doctors and nurses in out-patient care: a cross-sectional study. BMC Fam Pract. 2009;10:35. https://doi.org/10.1186/1471-2296-10-35.

40. Kopits IM, Chen C, Roberts JS, Uhlmann W, Green RC. Willingness to pay for genetic testing for Alzheimer's disease: a measure of personal utility. Genet Test Mol Biomarkers. 2011;15(12):871-5. https://doi.org/10.1089/gtmb.2011. 0028.

41. Kristiansen IS, Gyrd-Hansen D, Nexoe J, Nielsen JB. Number needed to treat: easily understood and intuitively meaningful? Theoretical considerations and a randomized trial. J Clin Epidemiol. 2002;55(9):888-92.

42. Barry MJ, Edgman-Levitan S. Shared decision making--pinnacle of patientcentered care. N Engl J Med. 2012;366(9):780-1. https://doi.org/10.1056/ NEJMp1 109283.

43. Ekman I, Swedberg K, Taft C, Lindseth A, Norberg A, Brink E, et al. Personcentered care--ready for prime time. Eur J Cardiov Nursing. 2011;10(4):24851. https://doi.org/10.1016/j.ejcnurse.2011.06.008.

44. Dorte $\mathrm{G}-\mathrm{H}$, Jes $\mathrm{S}$. Discounting life-years: whither time preference? Health Economics. 1998;7(2):121-7. https://doi.org/10.1002/(SICI)10991050(199803)7:2<121:AID-HEC318>3.0.CO;2-H.

Ready to submit your research? Choose BMC and benefit from:

- fast, convenient online submission

- thorough peer review by experienced researchers in your field

- rapid publication on acceptance

- support for research data, including large and complex data types

- gold Open Access which fosters wider collaboration and increased citations

- maximum visibility for your research: over $100 \mathrm{M}$ website views per year

At BMC, research is always in progress.

Learn more biomedcentral.com/submissions 